\title{
Analysis on the security threat of caisson gravity wharf DONG Qi ${ }^{1, a}$, TANG Ting ${ }^{1, b^{\star}}$, Wei Zhuo-bin ${ }^{1, c}$ \\ ${ }^{1}$ Logistics Academy,Naval University of Engineering, Tianjin300450, China adq_1990@163.com, 'b*kublai@126.com, cweizhuobin@eyou.com
}

\begin{abstract}
The wharf is an important part of the national security system and economic development. The caisson gravity wharf is one of the main structural forms of the wharf in China. The security threat analysis of the system is of great significance to the safe and efficient operation of the wharf. Based on the characteristics of material, structure and working load of caisson gravity wharf, this paper summarizes the safety threats of terminals from both common diseases and occasional safety threats, covering the structural damage that may bring hidden danger to the safety of the structural damage, overall damage, man-made threat and natural threat. The possible failure modes and main causes of the structural wharfs are determined. It is also pointed out that the occasional safety threat may cause multiple failure modes of the caisson gravity wharf to cause serious safety accidents and secondary disasters. Finally, the paper puts forward the measures to reduce the safety risk of the wharf, improve the wharf's response to the threat and ensure the safe and efficient operation of the terminal.
\end{abstract}

Keywords: caisson; gravity wharf; security threat; failure mode

\section{Introduction}

Wharf for the development of the country has important strategic significance, is to support the national economic development an important foundation. Since the rapid development of wharf construction in modern times, the world economic development has made important contributions [1]. However, some terminals in the face of long-term service and large-scale development of ship transport, corrosion, aging, overload, fatigue and other causes of structural damage is becoming increasingly serious, many terminals have extended service or "sick" work and there are different In addition, the terminal natural and operating environment is complex, the terminal safety production by the typhoon, heavy rain, storm surge and other natural disasters have a greater impact; in recent years, frequent terrorism, but also as a national security system and an important part of economic development The terminal faces a more severe security threat. Under the influence and interaction of structural damage, natural and man-made disaster factors, the terminal faces a wide range of security threats. Therefore, it is of great significance to systematically analyze the potential security risks of the terminal and to grasp the security threats faced by the terminals. It is of great significance to improve the design level of the wharf, to develop the economic and reasonable terminal maintenance and reinforcement scheme and to strengthen the management of the wharf transportation. It is to ensure the efficiency and safety of the terminal an important basis for operations [2].

The caisson gravity wharf is stable against its own weight (including the weight of the packing in the structure and its structure), resisting various types of loads based on post-wall earth pressure, wave flow and ship load, avoiding possible sliding and overturned [3]. The caisson terminal structure can withstand large loads, adaptability to the terminal and ship overload, and is suitable for all kinds of rock foundation, 
sandy and hard clay foundation, especially for the higher surface of the rock surface, is almost the only suitable structure. The application of the caisson wharf is simple and the cost is low. The maintenance cost is low during the use period, and the adaptability to the change of the loading and unloading process is strong. Technology is simple and strong to adapt to the ability to work to become China has been built and under construction in the main structure of the wharf, in the sea, the river are widely used. Based on the existing data, specifications and materials and structural characteristics, this paper summarizes the failure modes and incentives that may occur during the operation of the wharf by analyzing the common damage and incidental safety threats of the caisson gravity terminal and the preliminary suggestions to reduce the safety risk and raise the threat coping with the ability to suggest.

\section{Common damage analysis}

In the actual engineering caisson gravity wharf often presents show low maintenance costs and partial damage is not easy to repair the dual characteristics of the use of the operation may occur in a variety of different types of damage, these damage the light of the normal use of the structure, shorten the structure of service time, those who will endanger the use of safety [4]. At the same time, the "sick" work of the terminal to deal with occasional artificial or natural security threats to the security reserves are limited, may bring more serious losses and secondary disasters. The reasons for the damage of the caisson gravity wharf structure are complex, which are as follows: (1) The design code of the existing wharf construction period and the limitation of the construction quality; (2) The ship and the loading and unloading process are developing rapidly in the long term, and many of the design load factors and conditions, the structure prone to varying degrees of damage. (3) Structural changes in the environment, natural and working conditions change caused by changes in the working environment, vessel impact, material aging, corrosion and changes in foundation conditions and other factors [4]. Common damage that may cause failure of the caisson wharf can be summed up from both local damage and overall.

\subsection{Local damage}

The caissons and the walls are the main components of the caisson gravity wharf building, which provides the upright wall required for the berth, the working surface of the wharf equipment and the maintenance of the partial stability of the wharf as a whole [5]. Damage to the component will directly lead to damage to the working face of the wharf, a direct result of reduced ability to work. Long-term component damage can also lead to long-term or sudden overall damage or failure of the wharf, which is a major security risk. The reinforced concrete structure has the advantages of low cost and strong adaptability, which is the main structure of the caisson and the chest wall. Generally speaking, the durability of reinforced concrete structure is better, but the wharf structure is more in the harsh marine environment, corrosive atmosphere environment, the aging of the material and erosion is more serious, the structure itself is more prone to damage and damage, a serious shortage of durability, A direct impact on the overall structure of the security and applicability. At the same time, the damage of the underwater part of the wharf structure is difficult to be found in time, and the steel quantity of the structure is large, and the damage degree is easy to increase rapidly. It is divided into the following forms:

(1) Chest wall cracking, damage;

(2) Track beam cracks;

(3) The damage of the thin - walled reinforced concrete wall members and the caisson 
cracking;

(4) Erosion and erosion;

(5) Concrete carbonation and corrosion of steel corrosion.

2.2 Overall damage

The caisson structure mainly relies on its own weight to maintain its stability in the complex working environment, while the foundation also bear a large self-weight pressure. For the whole, the damage is mainly manifested by the level and vertical displacement of the structural structure caused by the imbalance of the structural resistance and its load effect in the dynamic change of the terminal structure during its whole life cycle, which makes the overall performance of the terminal decrease and the emergence of security threats. On the one hand the structure of the wharf itself and its surrounding packing in the long-term work of the loss and the aging of the caisson itself, damage caused by structural resistance decreased. On the other hand, the compressive deformation of the foundation and the post-structure and the change of the scouring and silting in the harbor will change the load effect. The overall damage to the wharf is mainly manifested in the following forms:

(1) Uneven settlement of the bed and foundation of the rubble;

(2) After the terminal wall fillers or wall fillers within the settlement;

(3) Changes in load and harbor erosion.

(4) Structural resistance or self-weight attenuation.

Non-standard survey design and unqualified construction quality are direct factors that lead to structural damage and large overall displacement. At the same time, the long-term impact of natural conditions change is difficult to predict, the terminal life cycle is long, design, construction to operation time span, by hydrology, geological conditions and other factors. The overall damage to the wharf structure is more risky and more incentives, once the repair is more difficult.

\section{Occasional security threat}

The wharf operation and the natural environment are complex, and the types of incidental security threats are diverse and have great harm. On the one hand, the wharf Multi operation involving more personnel, human factors difficult to control, while the open working environment for terrorist attacks and military attacks and other security threats to resist the poor. On the other hand, with the deterioration of the global natural environment, the frequent occurrence of natural disasters, in the complex natural environment of the wharf, the potential natural disaster prediction is difficult and difficult to avoid, open and hydrophilic characteristics make the natural disaster into a safe and efficient operation of the wharf a major threat. In general, it is possible to summarize the occasional security threats that the wharf may face from both the human-induced threat and the natural disaster threat.

3.1 Threat of man-made disaster

From the point of view of human factors and social factors, the wharf is more active in the area where the economy is busy and the sea is busy. The busy operation of the wharf may encounter in the economically active and maritime transportation area where the wharf is busy. The wharf cargo contains fuel and various threats Chemical engineering; wharf equipment and cargo volume; wharf operations involving personnel, more machinery, and production operations complex. In order to Tianjin Port "8.12" Ruihai company dangerous goods warehouse particularly major fire and explosion accidents and 7.16 Dalian Newport fire accident as the representative of the wharf in recent years, frequent wharf accidents are the wharf complex operating 
environment, port operations management and man-made production mistakes The risk of man-made disaster is characterized by multiple, randomness, severity and persistence, which can be divided into the following categories:

(1) Ship collision accident in Hong Kong;

(2) The forefront of the terminal production operations accident;

(3) Safety accidents in the port area;

(4) Terrorist attacks and military attacks.

3.2 Natural disaster threat

In recent years, with the intensity of natural disasters, the frequency and breadth of the growing, more in the open waters of the wharf facing the threat of natural environment is also more serious [6]. Natural conditions have a significant impact on the development of the wharf capacity, the efficient operation of the wharf, the functional play and the overall safety of the direct impact of natural disasters. Especially for the caisson gravity wharf, the stability of its own structure depends on the natural environment changes, sporadic natural disasters and persistent environment and hydrology may directly damage the overall stability of the structure. From the natural environment to the terminal operation and structural safety of the threat of disaster analysis, can be summarized as follows:

(1) Wind and waves continue to vicious effect;

(2) Typhoon and storm surge;

(3) Fog;

(4) Sea level rise;

(5) Earthquake effect.

\section{Failure modes and incentives}

Health of the wharf must meet the following functional requirements [7]: (1) in normal construction and normal use, can withstand the various possible effects; (2) in normal use, with good performance; (3) under normal maintenance, with sufficient durability; (4) in the expected accident occurred and after the occurrence, still able to maintain the necessary overall stability. Considering the common disease and potential incidental safety risks of the wharf, the failure modes and corresponding incentives that may occur in the caisson structure may be categorized as follows:

1) The wharf is slipping forward. Mainly by the rubble bed and the foundation of the uneven settlement; after the terminal wall fillers or wall fillers within the settlement; load and harbor erosion and other changes caused.

2) The wharf overturned damage. Mainly by the rubble bed and foundation of the uneven settlement; load and harbor erosion changes caused.

(3) The wharf concrete surface cracking, collapse. Mainly by the post-wall fillers or wall fillers within the settlement caused.

(4) The wharf cannot be used normally. Mainly cracked by the chest wall, broken; track beam cracks; thin-walled reinforced concrete wall components aging damage and caisson cracking; steel corrosion deterioration; concrete corrosion deterioration caused.

At the same time, occasional security threats are large, involving a wide range of hazards lasting, the same threat may lead to the failure of the wharf failure mode occurs, resulting in significant losses. For example, ships in the harbor area, production operations and yard accidents can directly cause damage to the terminal or 
cannot be used for a long time; terrorist attacks and military strikes and other deliberate damage, including typhoons, storms and earthquakes, including extremes natural disasters, will lead to sudden damage to the wharf structure of the damage and bring huge personal property damage; wind and waves continued to vicious effects and fog, sea level rise and other persistent natural changes will lead to failure of the wharf.

\section{Summary and recommendations}

Based on the existing data, specifications and materials and structural characteristics, this paper analyzes the common damage and incidental safety threats of caisson gravity wharf, points out the failure modes that may occur during the operation of the wharf and the common local and overall damage types. At the same time pointed out that the occasional security threat may also cause a variety of failure modes of caisson gravity wharf superposition occurred, resulting in major security incidents, bringing huge personal property losses. In order to reduce the safety risk of the wharf and improve the wharf's ability to deal with the threat, the caisson gravity wharf will face the safety and efficiency of the wharf in the life cycle and the production cycle. The following aspects:

(1) To strengthen the structure of health monitoring methods and testing methods to form a system of wharf health monitoring system, the wharf structure of the safety and performance of real-time monitoring for the timely construction of the wharf structure and efficient operation to provide scientific support. The structure health monitoring technology system is used for practical engineering, systematically collects and analyzes the monitoring data and application of the health monitoring system in the existing project, and provides a more comprehensive and reliable data support for the wharf health monitoring system for the safety of the caisson gravity wharf monitoring theoretical research to provide information and support.

(2) To combine the theoretical research and numerical simulation technology to carry out the research on the overall damage mechanism of the structure under different security threats and to provide reference and basis for the development of wharf design and wharf emergency plan.

(3) To establish the safety risk assessment system of the scientific system from the safety and threat identification of the caisson gravity wharf, and to establish a sound risk management system and a comprehensive safety contingency plan to ensure that Safe operation of the wharf.

(4) To improve the structural design and port planning level, for the specific functions or in a specific natural environment within the wharf to take special protective measures or structural design to improve the ability to deal with occasional security threats, reduce man-made and natural environment disaster to the wharf and the extent of the harbor.

(5) To strengthen the production safety hazard investigation, improve the wharf operating safety regulations and regulatory system. Strengthen the wharf operation and port security control, from the macro system operation to the micro-personnel management to start to form an organic safe operation system, reduce the possibility of security incidents.

\section{References}

[1] J.B. Guo. Based on support vector machine gravity dock structure health monitoring and forecasting model[D]. Zhejiang University of Technology,2013. 
[2] C.H. Huang, Z.B. Wei. Structural health monitoring of harbor terminals[J]. Water Transport Engineering, 2009 (4): 106-109.

[3] JTJ 290-89. Gravity-type wharfs design and construction specifications [S].

[4] F. Yang. Water dock structure disease mechanism and its countermeasures[D]. Wuhan University of Technology,2009.

[5] J. Qiu. Hong Kong workers building[M]. Tianjin University Press,2002.

[6] S.Y. Xu, Wang Jun, Shi Chun, et al. Study on natural disaster risk in coastal cities [J]. Chinese Journal of geography, 2006, 61 (2): 127-138.

[7] Q.F. Shi. The high pile wharfs structure safety assessment [D]. Chongqing Jiaotong University, 2010 